\title{
$\mathrm{R} C \& \mathrm{C}$
}

REVISTA DE CONTABILIDADE E CONTROLADORIA

A PRODUÇÃO CIENTÍFICA BRASILEIRA SOBRE

CONTABILIDADE TRIBUTÁRIA EM PERIÓDICOS E EVENTOS NO PERÍODO DE 1989-2011

\section{THE SCIENTIFIC PRODUCTION ON TAX ACCOUNTING IN BRAZILIAN JOURNALS AND EVENTS IN THE PERIOD OF 1989-2011}

Recebido em 08.08.2013 | Aceite final em 25.01.2014 |

Nota: este artigo foi aceito pelo Editor Jorge Eduardo Scarpin e passou por uma avaliação double blind review

A reprodução dos artigos, total ou parcial, pode ser feita desde que citada a fonte.

\section{ANTONIO CARLOS CAMPODONIO ELOY JUNIOR}

Acadêmico do Curso de Ciências Contábeis | Universidade Federal de Santa Catarina | Campus Universitário Reitor João David Ferreira Lima | Bairro Trindade | Florianópolis-SC | Brasil | CEP 88040-900 |Telefone (+5548) 3304-7867 | E-mail: juca_eloy@hotmail.com |

\section{SANDRO VIEIRA SOARES}

Doutorando em Controladoria e Contabilidade | Universidade de São Paulo | Avenida Professor Luciano Gualberto, 908 | Cidade Universitária | São Paulo-SP |Brasil | CEP 05508-010 | Telefone (+5548) 3721-6622 | E-mail: sandrovs@usp.br |

\section{MARIA DENIZE HENRIQUE CASAGRANDE}

Doutora em Engenharia de Produção | Universidade Federal de Santa Catarina | Professora da Universidade de Santa Catarina | Departamento de Ciências Contábeis | Centro Sócio-Econômico | Campus Universitário Reitor João David Ferreira Lima | Sala 114 | Trindade | Florianópolis-SC | Brasil | CEP 88040900 | Telefone (+5548) 3721-6622 | E-mail: denize_casagrande@yahoo.com.br |

\section{RESUMO}

A Contabilidade Tributária é uma das áreas mais antigas, desenvolvidas dentro da Contabilidade, de tal modo que há autores que ligam a função de coletor de impostos à origem da figura do contador. A partir desse conhecimento, esta pesquisa pretende identificar o "estado da arte" da Contabilidade Tributária, segundo as pesquisas apresentadas nos periódicos e eventos de Contabilidade no Brasil. Para tanto, fez-se um estudo descritivo e bibliométrico, com abordagem de dados quali-quantitativa. Foram delimitados, então os artigos oriundos de periódicos mantidos por programas de pós-graduação em Contabilidade e eventos científicos classificados como E1, com áreas temáticas de Contabilidade, segundo o 
Qualis/Capes (2007-2009). Assim, de um total de 14.473 artigos, publicados em eventos; e 2.395, publicados em periódicos, levantou-se, ao todo, uma amostra de 200 artigos de Contabilidade Tributária, sendo 156 oriundos de eventos científicos e 44 de periódicos. Desse total, a área de Contabilidade Tributária representou cerca de $1 \%$ das publicações desses eventos e periódicos analisados. O padrão Lotka, observado nos artigos, revelou que em torno de $78,5 \%$ dos autores publicaram um artigo apenas. Os três autores mais prolíficos foram: Luiz Antônio Abrantes, com 17 publicações; Mauro Fernando Gallo, com 10 publicações; e Carlos Alberto Pereira, com 9 publicações.

Palavras-chave: Contabilidade Tributária. Bibliometria. Periódicos. Eventos.

\begin{abstract}
The Tax Accounting is one of the oldest areas developed within the Accounting, so that there are authors who relate the function of tax collector as the origin of the profession of Accountant. Thus, this research presents as a problem-situation the following question: How is the "state of art" of Tax Accounting, according to researchers presented in Accounting journals and conferences in Brazil? For this, the research aimed to identify the profile of academic surveys on Tax Accounting in Brazil. To do so, it was made a descriptive and bibliometric study, with qualitative and quantitative data approach. For this study, were limited articles from journals kept by Accounting graduate programs and scientific events with thematic areas related to Accounting, which were classified as E1, according to Qualis/CAPES (2007-2009). From 14.473 articles published in scientific events and 2.395 articles published in journals, it was verified a sample of 200 tax accounting articles, being 156 derived from events and 44 from scientific journals. As a whole, Tax Accounting area represented about $1 \%$ of publications in the journals and events analyzed. The Lotka pattern observed in the articles revealed that around $78.5 \%$ of the authors published only one article. The three most prolific authors were: Luiz Antonio Abrantes, with 17 papers; Mauro Fernando Gallo, with 10 and Carlos Alberto Pereira with 9 papers.
\end{abstract}

Keywords: Tax Accounting. Bibliometrics. Journals. Congress.

\title{
1. INTRODUÇÃO
}

A produção científica se faz necessária à medida que uma determinada área do conhecimento surge e precisa se consolidar no "mundo acadêmico". Com a Contabilidade, isso não é diferente. A Contabilidade Tributária é uma das várias especializações em que se desdobra a Contabilidade enquanto ciência social aplicada. Ela está presente na academia, dentro dos cursos de graduação e pós-graduação, mas, principalmente, está ligada a atividades do Contador no mercado profissional.

Dentro da área acadêmica, a pesquisa em Contabilidade Tributária tem como foco principal o planejamento tributário, como forma de elisão fiscal; o uso de sistemas informatizados de escrituração contábil (SPED e NF-e) e a educação continuada, como forma de atualização profissional 
sobre a legislação tributária, entre outros. No entanto, o que se tem visto em periódicos e eventos científicos, é que, embora a área da Contabilidade Tributária contemple uma variedade de temas, um número relativamente reduzido de artigos tem sido desenvolvido ou apresentado no meio acadêmico.

Diante disso, chega-se a questão-problema que dá origem a esta pesquisa: Como se encontra o "estado da arte" da Contabilidade Tributária, segundo as pesquisas apresentadas nos periódicos e eventos de Contabilidade no Brasil? E, para responder a essa pergunta estabelece-se como objetivo desta pesquisa identificar o perfil das publicações acadêmicas (artigos) publicadas em periódicos online, mantidos por programas de pós-graduação stricto sensu em Contabilidade e nos eventos classificados como E1, com áreas temáticas de Contabilidade, segundo o Qualis/Capes (2007-2009) da área de Administração, Contabilidade e Turismo, no Brasil.

Esta pesquisa encontra justificativa no fato de que a Contabilidade Tributária é um dos ramos das atividades contábeis que mais agregam Contadores nos nichos de mercado, mas não apresenta a mesma expressividade em relação às outras especializações da Contabilidade dentro da Academia. Outra justificativa para este estudo é que não há, na literatura acadêmica, um estudo que se proponha a analisar a bibliometria de Contabilidade Tributária com este escopo. Por fim, vale lembrar o grande número de tributos que há no Brasil,o que, sob certo aspecto, dá mais importância ainda para a Contabilidade Tributária (CASAGRANDE, 2006).

\section{REVISÃO DE LITERATURA}

Esta revisão de literatura é composta por duas seções: Contabilidade Tributária, na qual se conceitua o que é a Contabilidade Tributária; e Bibliometria, em que se apresenta o que é a bibliometria e quais são seus principais usos.

\subsection{CONTABILIDADE TRIBUTÁRIA}

A Contabilidade Tributária é uma das especializações mais antigas dentro da Contabilidade. Há quem diga que as duas tiveram uma origem comum com a criação dos tributos, nas mais antigas civilizações. $\mathrm{O}$ apóstolo Mateus, autor do evangelho homônimo e patrono da Contabilidade, era um coletor de impostos (MARQUES, 2010).

No Brasil, a Contabilidade Tributária vem sendo tratada dentro dos currículos dos cursos de negócios sob a forma de legislação fiscal ou alfandegária desde o seu surgimento no século XIX (SOARES et al., 2011). Revisando a literatura acerca de currículos de Contabilidade, não é difícil encontrar aspectos de Contabilidade Tributária sendo ministrados em disciplinas que não possuem tal nomenclatura, como na pesquisa de Theóphilo et al. (2000), por exemplo, que afirmam ter encontrado aspectos fiscais sendo trabalhados na disciplina de Teoria da Contabilidade.

Nos tempos atuais, praticamente, todos os cursos de Ciências Contábeis possuem disciplina específica sobre Contabilidade Tributária. O Conselho Federal de Contabilidade (CFC) sugere, por meio de sua "Proposta nacional de conteúdo para o curso de graduação em Ciências Contábeis", que o currículo do curso possua a oferta das disciplinas "Direito e Legislação Tributária" e "Planejamento e Contabilidade Tributária", conforme evidenciado no Quadro 1. 
Quadro 1: Disciplinas segundo a proposta do CFC

\section{DIREITO E LEGISLAÇÃO TRIBUTÁRIA}

Ementa: Aspectos Legais do Direito Tributário; Competência Tributária; Receitas Públicas e Tributos; Normas Gerais de Direito Tributário; Ilícito Tributário; Contencioso Tributário.

Objetivos: Conhecer e compreender a relação entre o Fisco e o Contribuinte, os princípios básicos e as normas que regem o Direito e a legislação tributária e complementar, o orçamento, os tributos, as obrigações, a estrutura e o funcionamento da administração pública fiscal, bem como o ilícito e o contencioso tributário.

Carga-horária: 90 horas-aula.

Fonte: Carneiro (2008).

Como se pode notar, ambas as disciplinas, embora próximas, têm ementas e objetivos distintos, sendo que essa distinção entre Legislação Tributária e Contabilidade Tributária é fundamental dentro do escopo desta pesquisa.

ludícibus, Martins e Gelbcke (2007, p. 29) afirmam que a Contabilidade é um "sistema de informação e avaliação, destinado a prover seus usuários, com demonstrações e análises de natureza econômica, financeira, física e de produtividade, com relação à entidade, objeto de contabilização" (grifo nosso).

Para Fabretti (2006, p. 29), a Contabilidade Tributária é "o ramo da Contabilidade que tem por objetivo aplicar, na prática, conceitos, princípios e normas básicas da Contabilidade e da legislação tributária, de forma simultânea e adequada". Ainda sobre o tema, Oliveira et al. (2006, p. 36) conceituam a Contabilidade Tributária como "o ramo da Contabilidade responsável pelo gerenciamento dos tributos incidentes nas mais variadas operações realizadas por uma empresa, ou grupo de empresas, adaptando ao dia-a-dia empresarial as obrigações tributárias, de forma a não expor a entidade às possíveis sanções fiscais e legais".

É a partir desses conceitos, propostos por Fabretti (2006), Oliveira et al. (2006) e ludícibus, Martins e Gelbcke (2007), que se delimitou esta pesquisa dentro do escopo da Contabilidade e excluindo a área do Direito. Assim sendo, as discussões teóricas e jurídicas sobre os mais diversos aspectos da legislação tributária nacional e internacional, que se dão no âmbito do direito, não são abordadas nesta pesquisa.

\subsection{BIBLIOMETRIA}

Pritchard (1969) foi quem sugeriu o termo "bibliometria" em seu artigo Statistical Bibliography or Bibliometrics, em referência à utilização de métodos matemáticos e estatísticos para quantificar os processos de comunicação escrita (GUEDES; BORSCHIVER, 2005). A pesquisa bibliométrica consiste na técnica estatística e quantitativa de aferição e análise do curso de disseminação do saber científico. As principais leis bibliométricas são a Lei de Lotka, a Lei de Zipf e a Lei de Bradford (GUEDES; BORSCHIVER, 2005). A Lei de Lotka ou índice de Lotka tem o intuito de mensurar a concentração e a produtividade dos autores (ALVARADO, 2009); já a Lei de Zipf ou, também, Lei do Mínimo Esforço consiste em quantificar a frequência de palavras-chave em um texto (VANTI, 2002); e, por fim, a Lei de Bradford, que avalia a produtividade dos autores em periódicos (PINHEIRO, 1983).

Para Vanti (2002), as técnicas bibliométricas possuem algumas possibilidades de aplicação, tais como: (i) identificar as tendências e a expansão de uma área; (ii) prever tendências de publicação;

Revista de Contabilidade e Controladoria, ISSN 1984-6266

Universidade Federal do Paraná, Curitiba, v. 6, n.1, p. 89-102, jan./abr. 2014. 
(iii) prever a produtividade de autores individuais, organizações e países; (iv) identificar as revistas do núcleo de uma disciplina; (v) medir o crescimento de determinadas áreas e o surgimento de novos temas; e (vi) analisar a fonte de dados utilizada nos estudos.

Splitter e Rosa (2012) analisaram o perfil dos artigos bibliométricos de Contabilidade e observaram que houve um aumento expressivo desses estudos publicados em eventos e periódicos na área de Contabilidade. Segundo essas mesmas autoras, faz-se necessário o desenvolvimento de estudos genéricos sobre alguns temas quanto ao "estado da arte" de alguns ramos da Contabilidade, como a Gerencial, a Financeira e a de Custos.

Outros autores não analisam apenas a produção científica sobre os ramos da Contabilidade, mas também o perfil de publicação dos eventos e periódicos como Ensslin e Silva (2008) que compararam as características bibliométricas dos artigos publicados no Congresso USP de Controladoria e Contabilidade e Iniciação Científica em Contabilidade e no Congresso UFSC de Controladoria e Finanças e Iniciação Científica em Contabilidade (2004). Leite Filho e Siqueira (2007) analisaram os artigos publicados na Revista Contabilidade \& Finanças USP, no período compreendido entre 1999 e 2006. Espejo et al. (2009), compararam essa mesma revista com a The Accounting Review e buscaram delinear as principais características das publicações desses periódicos.

Gomes et al. (2007), ao avaliarem a produção científica nos Congressos USP de Iniciação Científica em Contabilidade nos, anos de 2004 a 2006, constataram que a maior parte das pesquisas ficavam concentradas em alguns temas, como a Contabilidade Gerencial, Educação e Pesquisa Contábil, Contabilidade Social e Ambiental, e Contabilidade de Custos.

\section{METODOLOGIA}

Este estudo é classificado como uma pesquisa descritiva, quanto ao objetivo, conforme Gil (1999); com uma abordagem de dados quali-quantitativa, segundo Richardson (1999); e trata-se de uma pesquisa bibliométrica, baseada em artigos publicados em revistas e eventos científicos. A trajetória metodológica desta pesquisa teve início com a delimitação criteriosa da população de revistas e eventos acadêmicos para a coleta de dados.

Segundo o Qualis da área de Administração, Contabilidade e Turismo, atualizado em 2012, existem 875 periódicos, classificados entre o estrato A1 e B5, utilizados por pesquisadores da área de gestão e negócios, para divulgação de suas pesquisas. No entanto, muitas dessas revistas, pertencem, $a$ priori, a outras áreas do conhecimento. Outras dessas revistas, mesmo ligadas a cursos de Administração, possuem um escopo de publicação de trabalhos que não contemplam artigos oriundos da área de Contabilidade.

Com isso em mente, para a definição do conjunto de revistas que seria estudado, decidiu-se por escolher todas as revistas ligadas ou mantidas por programas de pós-graduação stricto sensu, on-line, em Contabilidade, ofertados no Brasil. São elas: Contabilidade Vista e Revista; Revista Contabilidade e Finanças; Contabilidade, Gestão e Governança; Contextus - Revista Contemporânea de Economia e Gestão; Revista de Contabilidade do Mestrado em Ciências Contábeis da Universidade do Estado do Rio de Janeiro (UERJ); Brazilian Business Review; Base - Revista de Administração e Contabilidade da Unisinos; Revista Brasileira de Gestão de Negócios; Revista Contemporânea de Contabilidade; Revista Universo Contábil; Sociedade, Contabilidade e Gestão; Revista de Informação Contábil; Revista de Contabilidade da Universidade Federal da Bahia (UFBA); Revista Contabilidade e Organizações e Revista Contabilidade e Controladoria.

As revistas analisadas foram criadas entre os anos de 1989 e 2009. A Revista de Contabilidade do Mestrado em Ciências Contábeis da UERJ foi criada em 1996 como Revista do Núcleo Superior de Estudos Governamentais (NUSEG), mas, em seu formato atual, ela possui edições on-line desde 2003. A Revista Contabilidade e Finanças possui suas edições on-line a partir de 2001. Antes disso, suas 
edições saíam sob a denominação de Cadernos de Estudos, sendo que estas edições também foram consideradas pelos autores para esta pesquisa.

Por sua vez, o Documento de Área 2009, da área de Administração, Ciências Contábeis e Turismo, elenca uma lista de 106 eventos classificados nos estratos E1 (45) e E2 (61). Da mesma forma, nem todos os eventos são da área, e tampouco todos os eventos da área incluem a Contabilidade como escopo. Sendo assim, os autores decidiram por utilizar dois critérios para seleção da amostra: 1) Eventos classificados como E1, que é o nível superior ao E2; e 2) Eventos que possuíam alguma linha de interesse ou área temática em Contabilidade. Logo, a amostra desta pesquisa foi composta por cinco eventos: Congresso Brasileiro de Custos (CBC); Encontro da Associação Nacional de PósGraduação e Pesquisa em Administração (EnANPAD); Congresso USP de Controladoria e Contabilidade e Congresso USP de Iniciação Científica; Encontro de Ensino e Pesquisa em Administração e Contabilidade (EnEPQ); e Encontro da Associação dos Programas de Pós-Graduação em Ciências Contábeis (ANPCONT).

Dos cinco eventos E1, com áreas temáticas em Contabilidade, todos eles possuem seus anais on-line, sendo que dois deles mantém o acesso aberto para os trabalhos na íntegra - USP e ANPCONT, enquanto que os demais permitem acesso apenas ao resumo. Os autores optaram por incluir os artigos do Congresso de Iniciação Científica da USP na análise, assim como os artigos do FastTrack da ANPCONT.

A coleta de dados ocorreu entre os dias 02 e 16 de maio de 2012, diretamente nos sites das revistas, nos sites dos eventos, ou nos CDs dos anais dos eventos. Buscou-se identificar todos os artigos com a temática tributária, tais como "impostos", "taxas", "fiscal", "ICMS", "ISS" e "SPED", que estavam ligados a Contabilidade. Aqueles artigos que possuíam as palavras-chave delimitadas, mas não estavam relacionados à Contabilidade foram desconsiderados. Para que o estudo bibliométrico se realizasse, foram levantadas as seguintes informações:

- Frequência de publicação de artigos sobre Contabilidade Tributária em eventos e periódicos;

- Evolução temporal dos artigos sobre Contabilidade Tributária publicados nos eventos e periódicos;

- Referências bibliográficas utilizadas e quantidade média de referências por artigos;

- Número de autocitações;

- Subáreas mais abordadas;

- Autores mais prolíficos;

- Quantidade de autores por artigo e gênero dos autores; e

- Lei de Lotka ou índice de Lotka.

O índice proposto por Lotka (1926), que mensura o grau de produtividade dos autores, e que será analisado neste artigo, é calculado por meio da seguinte fórmula: $a_{n}=a_{1} / n^{c}$, onde $a_{n}$ corresponde ao número de autores com $\mathrm{n}$ artigos; $a_{1}$ corresponde ao número de autores que publicaram apenas um artigo; e $n$ corresponde ao número de artigos; e $c$ corresponde ao coeficiente de Lotka $(\approx 2)$. Os autores deste estudo preferiram dar ênfase à aplicação da Lei de Lotka em detrimento das demais leis bibliométricas, visto que, segundo Ensslin e Silva (2008), essa lei é a mais utilizada nos estudos bibliométricos em Contabilidade.

Para o enquadramento dos artigos nas subáreas mais abordadas, foi elaborada uma classificação de acordo com o assunto discutido pelos autores dos artigos a fim de identificar as subáreas mais pesquisadas, como se expõe no Quadro 2. 
Quadro 2: Classificação das subáreas de pesquisa em Contabilidade Tributária CLASSIFICAÇÃO DAS SUBÁREAS E O ASSUNTO

Administração Tributária: Fiscalização e arrecadação de tributos; Guerra fiscal; Evasão fiscal; Escrituração

1 fiscal digital.

Custos e Impactos Tributários: Impacto dos tributos na cadeia econômica; Custo real dos tributos; Reflexo

2 da cumulatividade e da não-cumulatividade de tributos; Desoneração de impostos e suas consequências.

Ensino e Pesquisa: Epistemologia da pesquisa tributária; Contabilidade Tributária sob o enfoque do ensino

3 em instituições de ensino.

Extrafiscalidade: Concessão de incentivos fiscais por parte do Governo; Redução de alíquotas de um tributo

4 para estimular determinado setor da economia.

Legislação Tributária: Análise da alteração da legislação de tributos; Propostas de reforma tributária;

5 Legislação Tributária x Societária.

Planejamento Tributário: Aspectos relacionados à Elisão Fiscal; Práticas contábeis aceitas pela legislação;

6 Economia de impostos nas diferentes organizações.

Regime de Tributação: Comparação entre empresas tributadas por diferentes regimes; Estudo individual dos

7 regimes de tributação: Lucro real, Lucro presumido e Simples Nacional.

Alguns artigos apresentaram afinidade com mais de uma subárea, entretanto levou-se em conta a predominância do assunto mais abordado para que se efetuasse a classificação. Vale ressaltar que a elaboração desta classificação não teve o intento de criar uma classificação da pesquisa de Contabilidade Tributária, apenas foram reunidos os temas mais discutidos em subtemas genéricos.

\section{ANÁLISE DOS RESULTADOS}

Nesta seção do estudo, serão apresentados os resultados da análise bibliométrica dos artigos coletados em eventos classificados como E1, com áreas temáticas de Contabilidade, segundo o Qualis/Capes (2007-2009), da área de Administração, Contabilidade e Turismo, no Brasil, e em periódicos mantidos por programas de pós-graduação em Contabilidade. A Tabela 1 apresenta a quantidade de artigos publicados em eventos até as edições de 2011 e a frequência de artigos que abordavam a temática tributária.

Tabela 1: Frequência de artigos sobre Contabilidade Tributária em eventos

\begin{tabular}{l|r|r|r}
\hline EVENTO & No DE ARTIGOS TRIBUTÁRIA & (\%) \\
CBC & 3.012 & 54 & $1,79 \%$ \\
\hline EnEPQ & 317 & 0 & $0,00 \%$ \\
\hline EnANPAD & 9.711 & 68 & $0,70 \%$ \\
\hline AnpCont & 380 & 1 & $0,26 \%$ \\
\hline USP & 1.053 & 33 & $3,13 \%$ \\
\hline Total & $\mathbf{1 4 . 4 7 3}$ & $\mathbf{1 5 6}$ & $\mathbf{1 , 0 8 \%}$ \\
\hline
\end{tabular}

É possível observar que o ENEPQ foi o único evento que não possuía artigos relacionados à temática tributária. O Congresso USP de Controladoria e Contabilidade e Congresso USP de Iniciação Científica foi o evento que apresentou a maior proporção de artigos relacionados à Contabilidade Tributária. $O$ ANPCONT até a sua edição de 2011 apresentou um único artigo sobre Contabilidade Tributária.

A Tabela 2, na sequência, apresenta a quantidade de artigos publicados pelos periódicos até a última edição de 2011, que estavam disponíveis no período da coleta, e a frequência de artigos sobre Contabilidade Tributária. 
Tabela 2: Frequência de artigos sobre Contabilidade Tributária em periódicos

\begin{tabular}{|c|c|c|c|}
\hline PERIÓDICO & $\begin{array}{l}\text { NNo DE } \\
\text { ARTIGOS }\end{array}$ & $\begin{array}{c}\text { C. } \\
\text { TRIBUTÁRIA }\end{array}$ & (\%) \\
\hline Contextus - Revista Contemporânea de Economia e Gestão & 106 & 1 & $0,94 \%$ \\
\hline Brazilian Business Review & 129 & 3 & $2,33 \%$ \\
\hline Contabilidade Vista e Revista & 386 & 3 & $0,78 \%$ \\
\hline Revista de Informação Contábil & 109 & 7 & $6,42 \%$ \\
\hline Sociedade, Contabilidade e Gestão & 98 & 1 & $1,02 \%$ \\
\hline $\begin{array}{l}\text { Revista de Contabilidade do Mestrado em Ciências Contábeis da } \\
\text { UERJ }\end{array}$ & 115 & 3 & $2,61 \%$ \\
\hline Base - Revista de Administração e Contabilidade da Unisinos & 166 & 0 & $0,00 \%$ \\
\hline Revista Universo Contábil & 209 & 4 & $1,91 \%$ \\
\hline Revista Brasileira de Gestão de Negócios & 169 & 3 & $1,78 \%$ \\
\hline Revista de Contabilidade da UFBA & 71 & 2 & $2,82 \%$ \\
\hline Revista Contabilidade e Controladoria & 51 & 1 & $1,96 \%$ \\
\hline Revista Contemporânea de Contabilidade & 117 & 0 & $0,00 \%$ \\
\hline Contabilidade, Gestão e Governança & 193 & 4 & $2,07 \%$ \\
\hline Revista Contabilidade e Finanças & 370 & 10 & $2,70 \%$ \\
\hline Revista Contabilidade e Organizações & 106 & 2 & $1,89 \%$ \\
\hline Total & 2395 & 44 & $1,84 \%$ \\
\hline
\end{tabular}

Não foram encontrados artigos sobre a temática tributária na Revista Contemporânea de Contabilidade e na Revista de Administração e Contabilidade da Unisinos - Base. A Revista da Informação Contábil foi o periódico que apresentou a maior frequência de artigos relacionados à Contabilidade Tributária. Desse total de artigos publicados nos eventos e nos periódicos, a Contabilidade Tributária representou 200 artigos, cerca de 1,19\%.

A Tabela 3, a seguir, apresenta a evolução temporal da publicação de artigos nos eventos, bem como a evolução da produção de artigos voltados à Contabilidade Tributária.

Tabela 3: Evolução temporal da produção de artigos publicados em eventos.

\begin{tabular}{c|c|c|c|c|c|c|c}
\hline $\mathbf{A N O}$ & \multicolumn{1}{c}{ No DE ARTIGOS TRIBUTÁRIA } & $\mathbf{( \% )}$ & \multicolumn{1}{c}{ ANO } & \multicolumn{1}{c}{ No DE ARTIGOS TRIBUTÁRIA } & (\%) \\
$\mathbf{1 9 9 4}$ & $\mathbf{2 1}$ & 0 & $0,00 \%$ & $\mathbf{2 0 0 3}$ & $\mathbf{7 7 0}$ & 8 & $1,04 \%$ \\
\hline $\mathbf{1 9 9 5}$ & 84 & 0 & $0,00 \%$ & $\mathbf{2 0 0 4}$ & 1150 & 15 & $1,30 \%$ \\
\hline $\mathbf{1 9 9 6}$ & 46 & 0 & $0,00 \%$ & $\mathbf{2 0 0 5}$ & 1258 & 14 & $1,11 \%$ \\
\hline $\mathbf{1 9 9 7}$ & 291 & 4 & $1,37 \%$ & $\mathbf{2 0 0 6}$ & 1229 & 16 & $1,30 \%$ \\
\hline $\mathbf{1 9 9 8}$ & 327 & 1 & $0,31 \%$ & $\mathbf{2 0 0 7}$ & 1540 & 19 & $1,23 \%$ \\
\hline $\mathbf{1 9 9 9}$ & 378 & 1 & $0,26 \%$ & $\mathbf{2 0 0 8}$ & 1424 & 15 & $1,05 \%$ \\
\hline $\mathbf{2 0 0 0}$ & 503 & 1 & $0,20 \%$ & $\mathbf{2 0 0 9}$ & 1405 & 15 & $1,07 \%$ \\
\hline $\mathbf{2 0 0 1}$ & 559 & 1 & $0,18 \%$ & $\mathbf{2 0 1 0}$ & 1340 & 20 & $1,49 \%$ \\
\hline $\mathbf{2 0 0 2}$ & 752 & 2 & $0,27 \%$ & $\mathbf{2 0 1 1}$ & 1396 & 24 & $1,72 \%$ \\
\hline
\end{tabular}

O ano de 2011 pode ser considerado o ano de maior participação da temática tributária nas pesquisas publicadas nos eventos analisados. É possível afirmar que a pesquisa em Contabilidade Tributária vem se consolidando com o passar das edições dos eventos, embora ainda seja com uma frequência pequena. O triênio 1994-1996, quando existia apenas o CBC como congresso voltado à área de Contabilidade, não registrou trabalhos publicados sobre Contabilidade Tributária.

O número de artigos publicados aumentou expressivamente em alguns períodos, especialmente em 1997, 2004 e 2007, quando haviam sido criados, respectivamente, os eventos EnANPAD, o Congresso USP de Iniciação Científica, e os eventos ENEPQ e ANPCONT. A Tabela 4 retrata a evolução temporal da publicação de artigos em periódicos, além de apresentar a quantidade de artigos com a temática tributária. 
Tabela 4: Evolução da produção de artigos publicados em periódicos

\begin{tabular}{|c|c|c|c|c|c|c|c|}
\hline ANO & № DE ARTIGOS & TRIBUTÁRIA & (\%) & ANO & № DE ARTIGOS & TRIBUTÁRIA & (\%) \\
\hline 1989 & 12 & 0 & $0,00 \%$ & 2001 & 42 & 0 & $0,00 \%$ \\
\hline 1990 & 11 & 1 & $9,09 \%$ & 2002 & 48 & 1 & $2,08 \%$ \\
\hline 1991 & 13 & 0 & $0,00 \%$ & 2003 & 98 & 1 & $1,02 \%$ \\
\hline 1992 & 31 & 1 & $3,23 \%$ & 2004 & 118 & 1 & $0,85 \%$ \\
\hline 1993 & 20 & 1 & $5,00 \%$ & 2005 & 150 & 2 & $1,33 \%$ \\
\hline 1994 & 8 & 1 & $12,50 \%$ & 2006 & 191 & 3 & $1,57 \%$ \\
\hline 1995 & 10 & 0 & $0,00 \%$ & 2007 & 231 & 4 & $1,73 \%$ \\
\hline 1996 & 20 & 0 & $0,00 \%$ & 2008 & 294 & 9 & $3,06 \%$ \\
\hline 1997 & 26 & 0 & $0,00 \%$ & 2009 & 314 & 6 & $1,91 \%$ \\
\hline 1998 & 55 & 1 & $1,82 \%$ & 2010 & 311 & 6 & $1,93 \%$ \\
\hline 1999 & 44 & 0 & $0,00 \%$ & 2011 & 312 & 5 & $1,60 \%$ \\
\hline 2000 & 36 & 1 & $2,78 \%$ & - & - & - & - \\
\hline
\end{tabular}

Nota-se que 2008 foi o ano que teve a maior frequência de artigos que abordavam Contabilidade Tributária. Nesse mesmo ano, a Revista da Informação Contábil, a Revista Universo Contábil e a Revista de Contabilidade do Mestrado em Ciências Contábeis da UERJ publicaram dois artigos cada. Desde 2002, pelo menos um artigo sobre a temática tributária tem sido publicado em algum desses periódicos, mostrando, assim, que este tipo de pesquisa, embora ainda seja menos frequente que outros temas, tem se consolidado na academia por meio dos periódicos.

A Tabela 5 apresenta os tipos de referências mais utilizadas pelos autores dos artigos publicados nos periódicos e nos eventos.

Tabela 5: Referências dos artigos coletados

\begin{tabular}{|c|c|c|c|c|}
\hline \multirow[t]{2}{*}{ REFERÊNCIA } & \multicolumn{2}{|c|}{ EVENTOS } & \multicolumn{2}{|c|}{ PERIÓDICOS } \\
\hline & QUANTIDADE & (\%) & QUANTIDADE & (\%) \\
\hline Dissertações & 99 & $2,99 \%$ & 19 & $1,99 \%$ \\
\hline Monografias/TCC & 37 & $1,12 \%$ & 8 & $0,84 \%$ \\
\hline Livros & 1259 & $38,05 \%$ & 318 & $33,33 \%$ \\
\hline Teses & 64 & $1,93 \%$ & 19 & $1,99 \%$ \\
\hline Artigos - periódicos & 564 & $17,04 \%$ & 246 & $25,79 \%$ \\
\hline Artigos - congressos & 127 & $3,84 \%$ & 60 & $6,29 \%$ \\
\hline Sites & 440 & $13,30 \%$ & 101 & $10,59 \%$ \\
\hline Legislação & 543 & $16,41 \%$ & 138 & $14,47 \%$ \\
\hline Outros & 176 & $5,32 \%$ & 45 & $4,72 \%$ \\
\hline (a) Total & 3309 & $100,00 \%$ & 954 & $100,00 \%$ \\
\hline (b) Total de artigos & 156 & - & 44 & - \\
\hline Média de referências ( $a / b)$ & 21,21 & - & 21,68 & - \\
\hline № de artigos com autocitação & 41 & - & 12 & - \\
\hline Frequência (\%) & $26,3 \%$ & - & $27,3 \%$ & - \\
\hline
\end{tabular}

É interessante observar que a referência bibliográfica mais utilizada pelos autores são os livros, que representam $37 \%$ das referências do total da amostra dos artigos de eventos e periódicos. Os dados também mostram que uma parcela significativa das referências dos artigos é de sites da web, sendo a 4a referência mais utilizada. Embora a grande maioria dos artigos tenha utilizado a legislação que se encontra na web, tal referência não foi classificada como "Sites". Na categoria "Outros", se encontram tipos de referências não compreendidos entre os apresentados, tais como revistas e jornais de grande circulação.

Em média, os 200 artigos da amostra possuíam em torno de 21,3 referências bibliográficas. Entretanto surgem casos extremos encontrados na amostra de periódicos como Januzzi et al. (2000), nos quais os autores abordaram sobre planejamento tributário e utilizaram somente cinco 
referências bibliográficas. $\mathrm{O}$ artigo com maior número de referências bibliográficas foi o de Lopes (2008), em que a autora discutia sobre o Sistema tributário português, tendo 55 referências bibliográficas utilizadas. Fadlalah, Martinez e Nossa (2012) utilizaram em seu artigo, sobre planejamento tributário e as práticas de responsabilidade social corporativa, 47 referências.

A frequência de autocitações nos artigos dos eventos e dos periódicos é quase idêntica. A frequência total de $26,5 \%$ indica que, aproximadamente, um em cada quatro trabalhos possui autocitação.

Com relação às subáreas mais pesquisadas, a Tabela 6 apresenta dados desta pesquisa em Contabilidade Tributária, divididos em quais subáreas os autores mais abordaram.

Tabela 6: Subáreas dos artigos coletados

\begin{tabular}{|c|c|c|c|c|}
\hline \multirow[t]{2}{*}{ SUBÁREAS } & \multicolumn{2}{|c|}{ EVENTOS } & \multicolumn{2}{|c|}{ PERIÓDICOS } \\
\hline & № ARTIGOS & (\%) & № ARTIGOS & (\%) \\
\hline Administração Tributária & 33 & $21,15 \%$ & 12 & $27,27 \%$ \\
\hline Custos e impactos tributários & 63 & $40,38 \%$ & 16 & $36,36 \%$ \\
\hline Ensino e Pesquisa & 2 & $1,28 \%$ & 1 & $2,27 \%$ \\
\hline Extrafiscalidade & 14 & $8,97 \%$ & 1 & $2,27 \%$ \\
\hline Legislação Tributária & 17 & $10,90 \%$ & 6 & $13,64 \%$ \\
\hline Planejamento Tributário & 16 & $10,26 \%$ & 7 & $15,91 \%$ \\
\hline Regime de Tributação & 11 & $7,05 \%$ & 1 & $2,27 \%$ \\
\hline Total & 156 & $100,00 \%$ & 44 & $100,00 \%$ \\
\hline
\end{tabular}

A subárea Custos e impactos tributários, onde se concentram artigos que avaliam os efeitos causados pelos tributos, sejam eles nas organizações individuais ou na cadeia econômica, foi a mais abordada dentre as demais na amostra total de artigos (39,5\%). A subárea Ensino e Pesquisa, composta por artigos que analisavam a epistemologia da pesquisa em Contabilidade Tributária ou avaliavam a Contabilidade Tributária como disciplina ministrada nas universidades, foi a que apresentou menos publicação. Para analisar a quantidade de autores por artigo, elaborou-se a Tabela 7, que apresenta, separadamente, os resultados sobre eventos e periódicos.

Tabela 7: Quantidade de autores por artigo

\begin{tabular}{l|c|c|c|c}
\multicolumn{1}{c}{ NÚMERO DE AUTORES } & \multicolumn{2}{c}{ EVENTOS } & QUANTIDADE & (\%) \\
\hline Um autor & 27 & $17,31 \%$ & 5 & $11,36 \%$ \\
\hline Dois autores & 42 & $26,92 \%$ & 11 & $25 \%$ \\
\hline Três autores & 50 & $32,05 \%$ & 17 & $38,64 \%$ \\
\hline Mais de três autores & 37 & $23,72 \%$ & 11 & $25 \%$ \\
\hline Total & $\mathbf{1 5 6}$ & $100,00 \%$ & $\mathbf{4 4}$ & $100,00 \%$ \\
\hline Média de autores por artigo & $\mathbf{2 , 6 6}$ & - & 2,86 & - \\
\hline
\end{tabular}

Cerca de $25 \%$ dos trabalhos pesquisados tinha pelo menos quatro autores, contudo a maioria dos artigos em contabilidade tributária vem tendo a colaboração de até dois autores. Aproximadamente um terço dos trabalhos vem sendo realizados por três autores. A frequência de artigos em que não há colaboração é maior em eventos do que nos periódicos. Artigos que possuíam dois autores possuem quase a mesma frequência em eventos e periódicos.

Foi possível observar que os autores do sexo masculino possuem uma maior participação nas publicações de artigos relacionados à Contabilidade Tributária tanto em eventos $(74,5 \%)$ como em periódicos $(78,6 \%)$. É possível eu isso ocorra pelo fato de a maioria dos pesquisadores e até profissionais da área contábil ser do sexo masculino. Para apresentar quais foram os autores mais prolíficos, em se tratando da temática de Contabilidade Tributária, primeiramente foi elaborada a Tabela 8, na qual são apresentados os autores que mais produziram artigos em eventos. 
Tabela 8: Autores mais produtivos em eventos

\begin{tabular}{|c|c|c|}
\hline AUTOR & $\begin{array}{l}\text { QUANTIDADE DE } \\
\text { ARTIGOS }\end{array}$ & $\begin{array}{c}\text { (\%) SOBRE O } \\
\text { TOTAL }\end{array}$ \\
\hline ABRANTES, L. A & 16 & $10,26 \%$ \\
\hline GALLO, M. F. & 10 & $6,41 \%$ \\
\hline PEREIRA, C. A. & 8 & $5,13 \%$ \\
\hline FARONI, W. & 5 & $3,21 \%$ \\
\hline $\begin{array}{l}\text { BRUNOZI JÚNIOR, A. C; COSTA, D. M. D.; CABELLO, O. G.; } \\
\text { NAKAO, S. H. }\end{array}$ & 4 & $2,56 \%$ \\
\hline
\end{tabular}

Observa-se que um único autor, dos oito mais prolíficos, é responsável por pouco mais de $10 \%$ da produção de artigos de Contabilidade Tributária em eventos, ou seja, poucos autores detêm uma maior aglomeração de artigos publicados. Isso pode ser explicado pela Lei de Lotka, segundo a qual a larga produção de artigos está concentrada em poucos autores. A Tabela 9 apresenta dados sobre os autores mais produtivos em periódicos.

Tabela 9: Autores mais produtivos em periódicos

\begin{tabular}{l|c}
\multicolumn{1}{c}{ AUTOR } & $\begin{array}{c}\text { QUANTIDADE DE ARTIGOS } \\
\text { EM QUE FOI AUTOR }\end{array}$ \\
\hline SOUZA, M. A. & 4 \\
\hline KRONBAUER, C. A. & 3 \\
\hline BERTOLUCCI, A. V.; BRUNOZI JÚNIOR, A. C.; ALVES FILHO, B. F.; NASCIMENTO, D. \\
T.; PAULO, E.; FORMIGONI, H.; ARAÚJO, I. J. C.; RIBEIRO FILHO, J. F.; ROJAS, J. M.; \\
ALMEIDA, L. B.; ALBERTON, L.; ABRANTES, L. A.; POHLMANN, M. C.; FERREIRA, \\
M. A. M.; GOUVÊA, M. A.; ANTUNES, M. T. P.; FARINA, M. C.; VARELA, P. S.; \\
IUDÍCIBUS, S.; LAGIOIA, U. C. T.
\end{tabular}

É possível observar que um único autor é responsável pela publicação de $9 \%$ dos artigos e, assim como no caso dos eventos, a maioria das publicações se concentra em um único autor. Entretanto, surge o problema dos artigos que já foram publicados em eventos. Do total da amostra de artigos publicados em revistas (44), 12 já haviam sido publicados em congressos.

Nesse sentido, a Tabela 10 apresenta a produtividade "líquida" dos autores, ou seja, a produtividade em eventos, adicionada a produtividade em revistas, e, por conseguinte, subtraída dos artigos publicados em revistas e que já haviam sido publicados nos eventos que são analisados neste artigo.

Tabela 10: Produtividade "líquida" dos autores em eventos e periódicos

\begin{tabular}{l|c|c}
\multicolumn{1}{c}{ AUTOR } & QUANTIDADE LIQQUIDA DE ARTIGOS & (\%) SOBRE O TOTAL \\
ABRANTES, L. A & 17 & $9,04 \%$ \\
\hline GALLO, M. F. & 10 & $5,32 \%$ \\
\hline PEREIRA, C. A. & 9 & $4,79 \%$ \\
\hline KRONBAUER, C. A.; SOUZA, M. A. & 6 & $3,19 \%$ \\
\hline BRUNOZI JÚNIOR, A. C; FARONI, W. & 5 & $2,66 \%$ \\
\hline
\end{tabular}

Para avaliar o padrão de Lotka (1926) dos artigos, levou-se em conta apenas a produtividade "líquida" dos autores. A Tabela 11 apresenta os resultados encontrados em comparação com o padrão de Lotka. 
Tabela11: Padrão de Lotka dos artigos de Contabilidade Tributária

\begin{tabular}{l|c|c|c}
\hline NÚMERO DE ARTIGOS POR AUTOR & QUANTIDADE DE AUTORES & $\mathbf{( \% )}$ & PADRÃO DE LOTKA \\
\hline 1 artigo & 285 & $78,5 \%$ & $60,8 \%$ \\
\hline 2 artigos & 50 & $13,8 \%$ & $15,2 \%$ \\
\hline 3 artigos & 15 & $4,1 \%$ & $6,8 \%$ \\
\hline 4 artigos & 6 & $1,7 \%$ & $3,8 \%$ \\
\hline 5 artigos & 2 & $0,6 \%$ & $2,4 \%$ \\
\hline 6 artigos & 2 & $0,6 \%$ & $1,7 \%$ \\
\hline 7 artigos & 0 & $0,0 \%$ & $1,2 \%$ \\
\hline Mais de 7 artigos & 3 & $0,8 \%$ & $8,1 \%$ \\
\hline Total & $\mathbf{3 6 3}$ & $\mathbf{1 0 0 , 0} \%$ & $\mathbf{1 0 0 , 0} \%$ \\
\hline
\end{tabular}

A Tabela 11 indica que 78,5\% dos autores publicou apenas um artigo, se comparado ao padrão de Lotka pelo qual esse percentual é um pouco menor, 60,8\%. A frequência de autores que publicou mais de um artigo é de, aproximadamente, $21,5 \%$. Uma parcela muito pequena dos autores, inferior a $1 \%$, publicou mais de sete artigos, enquanto que, no padrão de Lotka, essa frequência é de $8,1 \%$. Portanto, a premissa de que poucos pesquisadores publicam muitos artigos e muitos pesquisadores publicam poucos artigos se mostrou verdadeira na pesquisa em Contabilidade Tributária.

\section{CONSIDERAÇÕES FINAIS}

O objetivo geral deste estudo foi o de analisar como se encontra a produção científica sobre Contabilidade Tributária em eventos classificados como E1, com áreas temáticas de Contabilidade, segundo o Qualis/Capes (2007-2009), a área de Administração, Contabilidade e Turismo, no Brasil, e periódicos mantidos por programas de pós-graduação em Contabilidade. Ao todo, foram encontrados 156 artigos em eventos e 44 artigos em periódicos.

O estudo bibliométrico procurou evidenciar as principais características constantes nos artigos, tais como: frequência de publicações sobre Contabilidade Tributária em eventos e periódicos; evolução temporal da publicação sobre Contabilidade Tributária; número de autores por artigo; composição das referências bibliográficas utilizadas; autores mais produtivos; as subáreas mais pesquisadas; e o número de autocitações.

A partir da amostra de artigos coletados, chegou-se, em síntese, aos seguintes resultados:

- A pesquisa em Contabilidade Tributária representa uma fração de, aproximadamente, $1 \%$ das publicações em congressos, e inferior a $2 \%$ das publicações em periódicos;

- Apesar de o número de pesquisas em Contabilidade Tributária ter crescido ao longo do período analisado, o percentual continua sendo em torno de $1 \%$ das publicações;

- $76 \%$ dos artigos analisados possuem até três autores;

- Quanto ao gênero, o sexo masculino teve maior representatividade nas pesquisas;

- Entre os três tipos de referências mais utilizados, os livros foram a fonte bibliográfica mais adotada pelos autores dos artigos, seguido por artigos publicados em periódicos e legislação nacional e internacional;

- Os três autores mais produtivos de acordo com a amostra são: Luiz Antônio Abrantes, com 17 publicações; Mauro Fernando Gallo, com 10 publicações; e Carlos Alberto Pereira, com 9 publicações;

- A subárea que apresentou uma maior concentração de pesquisas foi a de Custos e impactos tributários, e a que teve menos frequência foi a de Ensino e Pesquisa; e 
- Pouco mais de $25 \%$ dos artigos publicados em eventos e periódicos possuíam autocitações.

Diante dos resultados obtidos é possível inferir que o tema Contabilidade Tributária não é muito procurado pelos pesquisadores da Academia. Sugere-se, para pesquisas futuras, a réplica deste estudo, comparando a publicação sobre Contabilidade Tributária em periódicos e eventos internacionais, para que se possam obter dados mais densos, a fim de comparar com a pesquisa nacional.

\section{REFERÊNCIAS}

ALVARADO, R. U. A lei de Lotka e a produtividade dos autores. Perspectivas em Ciência da Informação, v. 14, n. 3, p. 233-233, 2009.

CARNEIRO, J. D. (Coord.). Proposta nacional de conteúdo para o curso de graduação em Ciências Contábeis. Brasília: Fundação Brasileira de Contabilidade, 2008.

CASAGRANDE, M. D. H. Jogo de empresa na prática de ensino de contabilidade tributária. 2006. 144 f. Tese (Doutorado) - Universidade Federal de Santa Catarina, Centro Tecnológico. Programa de PósGraduação em Engenharia de Produção, Florianópolis-SC.

ENSSLIN, S. R.; SILVA, B. M. S. Investigação do perfil dos artigos publicados nos congressos de contabilidade da USP e da UFSC com ênfase na iniciação científica. Revista de Contabilidade $e$ Organizações, v. 2, n. 3, p. 113-131, 2008.

ESPEJO, M. M. S. B.; CRUZ, A. P. C.; LOURENÇO, R. L.; ANTONOVZ, T.; ALMEIDA, L. B. Estado da arte da pesquisa contábil: um estudo bibliométrico de periódicos nacional e internacionalmente veiculados entre 2003 e 2007. Revista de Informação Contábil, v. 3, n. 3, p. 94-116, 2009.

FABRETTI, L. C. Contabilidade tributária. 10 ed. São Paulo: Atlas, 2006.

FADLALAH, B. S. N.; MARTINEZ, A. L.; NOSSA, V. Planejamento tributário e as práticas de responsabilidade social corporativa. Revista Contabilidade e Controladoria, v. 4, n. 3, p. 7-23, 2012.

GIL, A. C. Métodos e técnicas de pesquisa social. 5. ed. São Paulo: Atlas, 1999.

GOMES, R. B.; SANTIAGO, H. L. F.; LIMA, A. E. A.; GOMES, M. C. S.; RIBEIRO FILHO, J. F.; PEDERNEIRAS, M. M. M. Um estudo sobre a produção acadêmica em Contabilidade: uma abordagem nos Congressos USP de Iniciação Científica em Contabilidade. In: CONGRESSO USP DE INICIAÇÃO CIENTífICA EM CONTABILIDADE, 4, 2007, São Paulo. Anais... São Paulo: FEA/USP, 2007.

GUEDES, V. L. S.; BORSCHIVER, S. Bibliometria: uma ferramenta estatística para a gestão da informação e do conhecimento, em sistemas de informação, de comunicação e de avaliação científica e tecnológica. In: ENCONTRO NACIONAL DE CIÊNCIA DA INFORMAÇÃO, 6., 2005, Salvador. Anais... Salvador: UFBA/ICB, 2005.

IUDíCIBUS, S.; MARTINS, E.; GELBCKE, E. R. Manual de contabilidade das sociedades por ações: aplicável às demais Sociedades. 7. ed. São Paulo: Atlas, 2007.

JANUZZI, L.; ALMEIDA, M. R.; CASTRO, P. N.; AMARAL, S. C.; NASCIMENTO, T. A.; BARROS, V. C. Planejamento tributário. Contabilidade, Gestão e Governança, v. 3, n. 2, p. 49-72, jul. 2000.

LEITE FILHO, G. A. L.; SIQUEIRA, R. L. Revista Contabilidade e Finanças USP: uma análise bibliométrica de 1999 a 2006. Revista de Informação Contábil, v. 1, n. 2, p. 102-119, out./dez., 2007.

LOPES, C. M. M. O sistema tributário português: complexidade e aplicação. Revista Universo Contábil. v. 4, n. 4, p. 140-163, out./dez. 2008.

LOTKA, A. J. The frequency distribution of scientific productivity. Journal of the Washington Academy of Sciences, v. 16, n. 12, p. 317-323, Jun 1926. 
MARQUES, W. L. Contabilidade geral I - segundo a Lei 11638/2007 das sociedades anônimas: passo a passo da contabilidade. Cianorte: Gráfica Vera Norte, 2010.

OlIVEIRA, L. M.; CHIEREgATO, R.; PEREZ JUNIOR, J. H.; GOMES, M. B. Manual de contabilidade tributária. 5. ed. São Paulo: Atlas, 2006.

PINHEIRO, L. V. R. Lei de Bradford: uma reformulação conceitual. Ciência da informação, v. 12, n. 2, p. 59-80, 1983.

PRITCHARD, A. Statistical bibliography or bibliometrics?. Journal of Documentation, v. 25, n. 4, p. 348349. dez. 1969.

RICHARDSON, R. J. Pesquisa social: métodos e técnicas. 3. ed. São Paulo: Atlas, 1999.

SOARES, S. V.; RICHARTZ, F.; VOSS, B. L.; FREITAS, C. L. Evolução do currículo de contabilidade no Brasil desde 1809. Revista Catarinense da Ciência Contábil, v. 10, n. 30, p. 27-42, 2011.

SPLITTER, K.; ROSA, C. A. Genealogia dos trabalhos bibliométricos em Contabilidade. In: CONGRESSO USP DE CONTROLADORIA E CONTABILIDADE, 12., 2012, São Paulo. Anais... São Paulo: FEA/USP, 2012.

THEÓPHILO, C. R.; SACRAMENTO, C. O. J.; NEVES, I. F.; SOUZA, P. L. O ensino da teoria da contabilidade no Brasil. Contabilidade Vista \& Revista, v. 11, n. 3, p. 3-10, dez. 2000.

VANTI, N. A. P. Da bibliometria à webometria: uma exploração conceitual dos mecanismos utilizados para medir o registro da informação e a difusão do conhecimento. Ciência da Informação, v. 31, n. 2, p. 152-162, 2002. 